OPEN ACCESS

Edited by:

Francisco Airton Castro Rocha, Federal University of Ceará, Brazil

Reviewed by:

Flavio Almeida Amaral, Federal University of Minas

Gerais, Brazil Wenfeng Tan,

Nanjing Medical University, China

*Correspondence:

Kentaro Uchida kuchida@med.kitasato-u.ac.jp

Specialty section: This article was submitted to Rheumatology, a section of the journal Frontiers in Medicine

Received: 29 April 2021 Accepted: 29 June 2021 Published: 27 July 2021

Citation:

Mukai M, Uchida K, Okubo T, Takano S, Matsumoto T, Satoh M Inoue $G$ and Takaso M (2021) Regulation of Tumor Necrosis Factor-a by Peptide Lv in Bone Marrow Macrophages and Synovium. Front. Med. 8:702126. doi: 10.3389/fmed.2021.702126

\section{Regulation of Tumor Necrosis Factor- $\alpha$ by Peptide Lv in Bone Marrow Macrophages and Synovium}

\author{
Manabu Mukai ${ }^{1}$, Kentaro Uchida ${ }^{1,2 *}$, Tadashi Okubo ${ }^{3}$, Shotaro Takano ${ }^{1}$, \\ Toshihide Matsumoto ${ }^{4}$, Masashi Satoh ${ }^{5}$, Gen Inoue ${ }^{1}$ and Masashi Takaso ${ }^{1}$ \\ ${ }^{1}$ Department of Orthopaedic Surgery, Kitasato University School of Medicine, Sagamihara, Japan, ${ }^{2}$ Shonan University of \\ Medical Sciences Research Institute, Chigasaki, Japan, ${ }^{3}$ Department of Laboratory Animal Science, Kitasato University \\ School of Medicine, Sagamihara, Japan, ${ }^{4}$ Department of Pathology, Kitasato University School of Medicine, Sagamihara, \\ Japan, ${ }^{5}$ Department of Immunology, Kitasato University School of Medicine, Sagamihara, Japan
}

Background: Bone marrow-derived monocytes/macrophages are recruited into synovial tissue, where they contribute to synovial inflammation in osteoarthritis through inflammatory cytokine production. Recent studies have suggested that V-Set and transmembrane domain-containing 4 (VSTM4) and its fragment, peptide LV, exhibit immunosuppressive activity on T cells and vascular endothelial growth factor (VEGF)-like activity, respectively. Given that evidence suggests that VEGF may play a role in macrophage function, we investigated peptide Lv-mediated regulation of inflammatory cytokines in bone marrow macrophages (BMMs) and synovial inflammation.

Method: To investigate the effects of peptide Lv, BMMs were stimulated with vehicle, LPS, or LPS + peptide Lv, and Tnfa, $/ 11 \mathrm{~b}$, //6, and Ifng expression were evaluated using quantitative PCR (qPCR). TNF- $\alpha$ and IFN- $\gamma$ production was measured using ELISA. To examine the effect of peptide Lv deficiency on macrophages and synovitis, peptide L v-deficient mice were generated using genome editing. LPS-induced Tnfa and Ifng expression and TNF- $\alpha$ and IFN- $\gamma$ production were evaluated in BMM isolated from wild-type and peptide Lv-deficient mice. Additionally, Tnfa and Ifng expression levels were compared between wild-type and peptide $L v$-deficient mice before and after knee injury.

Results: Peptide Lv suppressed the LPS-mediated elevation in TNF- $\alpha$ and IFN- $\gamma$. LPS stimulation significantly increased TNF- $\alpha$ and IFN- $\gamma$ production in BMM derived from peptide $L v$-deficient mice compared to wild-type mice. Synovial TNF- $\alpha$ expression in the injured knee was elevated in peptide $L v$-deficient compared to wild-type mice.

Conclusion: Peptide Lv suppressed TNF- $\alpha$ in macrophages and plays a role in synovial inflammation. Thus, peptide Lv may be a useful therapeutic target for synovitis.

Keywords: V-set and transmembrane domain-containing 4, peptide Lv, tumor necrosis factor- $\alpha$, macrophage, synovitis 


\section{INTRODUCTION}

The main features of knee osteoarthritis (KOA), a form of degenerative joint disease, are articular cartilage degeneration, osteophytosis, bone remodeling, fibrosis, and synovial hyperplasia (1). Evidence suggests that synovial inflammation may play a role in disease progression and structural changes in KOA (2).

Myeloid cells including macrophages and monocytes contribute to the production of inflammatory cytokines including tumor necrosis factor- $\alpha$, interleukin- $1 \beta$, and interleukin-6 in synovitis (3-5). These inflammatory cytokines promote cartilage degradation and pain in the osteoarthritic synovium $(4,5)$. Several studies have reported that bone marrowderived monocytes are recruited into synovial tissue, where they contribute to synovial inflammation through inflammatory cytokine production $(2,6,7)$. Further, we previously reported that bone marrow-derived myeloid populations were recruited into the synovium in a KOA mouse model (8). Therefore, regulation of macrophage/monocyte-secreted inflammatory cytokines may be an effective therapeutic strategy for treating synovial inflammation.

Recent evidence indicates that the V-Set and transmembrane domain-containing (VSTM) family of proteins plays a variety of roles in the body, including controlling $\mathrm{T}$ cell activity, tumor growth, and adipocyte differentiation (9-12). V-Set and transmembrane domain-containing 4 (VSTM4) is a transmembrane protein composed of 320 amino acids (aa). The VSTM4 fragment (human, aa 55-94; mouse aa 55-103), peptide Lv, augments L-type voltage-gated calcium channels and has similar biological actions to vascular endothelial growth factor (VEGF) $(13,14)$. VEGF is thought to regulate the inflammation process by promoting the polarization of M1 macrophages to M2 macrophages and inhibiting TNF- $\alpha$-mediated apoptosis (1517). Given that peptide Lv can activate VEGF signaling, we hypothesized that peptide Lv regulates macrophage activity and plays a role in synovial inflammation.

Here, we examined the role of peptide Lv on inflammatory cytokine expression in macrophages and synovial inflammation.

\section{METHODS}

\section{Animal Ethics}

All experimental protocols received approval from the Kitasato University School of Medicine Animal Care Committee (2020087). The study complied with the ARRIVE guidelines for the reporting of animal experiments. All methods were performed according to the guidelines for the proper conduct of animal experiments by the Science Council of Japan. All experiments were performed a minimum of two times.

\footnotetext{
Abbreviations: OA, osteoarthritis; VSTM4, V-Set and transmembrane domaincontaining 4; VEGF, vascular endothelial growth factor; BMM, bone marrow macrophages; LPS, lipopolysaccharide; TNF- $\alpha$, tumor necrosis factor- $\alpha$; IL- $1 \beta$, interleukin-1 $\beta$; IL-6, interleukin-6; IFN- $\gamma$, interferon- $\gamma$.
}

TABLE 1 | Sequences of the primers used in this study.

\begin{tabular}{|c|c|c|}
\hline Primer & Sequence $\left(5^{\prime}-3^{\prime}\right)$ & Product size (bp) \\
\hline Tnfa-F & CTGAACTTCGGGGTGATCGG & 122 \\
\hline Tnfa-R & GGCTTGTCACTCGAATITGAGA & \\
\hline$/ / 1 b-F$ & GCAACTGTTCCTGAACTCAACT & 89 \\
\hline$/ / 1 b-\mathrm{R}$ & ATCTIITGGGGTCCGTCAACT & \\
\hline $1 / 6-\mathrm{F}$ & CTGCAAGAGACTTCCATCCAG & 131 \\
\hline $1 / 6-\mathrm{R}$ & AGTGGTATAGACAGGTCTGTTGG & \\
\hline Ifng-F & AGACAATCAGGCCATCAGCAA & 134 \\
\hline Ifng-R & GGACCCCTGTGGGTTGTTGACC & \\
\hline Gapdh-F & AACTTGGCATTGTGGAAGG & 223 \\
\hline Gapdh-R & ACACATTGGGGGTAGGAACA & \\
\hline
\end{tabular}

\section{Preparation of Bone Marrow-Derived Macrophages}

BMMs grown in monocyte colony-stimulating factor (M-CSF) were established based on a protocol reported previously (18). In brief, bone marrow cells isolated from the femurs of C57BL/6J mice were cultured in $\alpha$-MEM with $100 \mathrm{ng} / \mathrm{ml} \mathrm{M-CSF}$ (BioLegend, San Diego, CA, USA). On the fourth day of culture, non-adherent cells were extracted and cultured for an additional 3 days in $\alpha$-MEM containing fresh M-CSF.

\section{Impact of Peptide Lv on LPS-Mediated Inflammatory Cytokine Expression}

BMMs were isolated from C57BL/6J mice as described above. Synthetic peptide Lv (DSLLAVRWFFAPDGSQEALMVKMTKLRIIQYYGNFSRTANQQRLRLLEE) was purchased from Phoenix Pharmaceuticals (Burlingame, CA, USA). Our pilot studies showed that while $1 \mu \mathrm{g} / \mathrm{ml}$ peptide Lv suppressed Tnfa expression, $0.1 \mu \mathrm{g} / \mathrm{ml}$ peptide $\mathrm{Lv}$ did not. Therefore, we used $1 \mu \mathrm{g} / \mathrm{ml}$ peptide Lv in this study.

BMMs were exposed to vehicle $(\alpha-\mathrm{MEM}), \quad 1 \mu \mathrm{g} / \mathrm{ml}$ lipopolysaccharide (LPS) (Enzo Life Sciences Inc., Farmingdale, NY, USA), or $1 \mu \mathrm{g} / \mathrm{ml} \mathrm{LPS}+1 \mu \mathrm{g} / \mathrm{ml}$ peptide Lv for 6 and $24 \mathrm{~h}$. Thereafter, total RNA was extracted from BMM and used for cDNA synthesis based on a previously published protocol. The sequences of primers used for qRT-PCR are listed in Table 1. Relative Tnfa, Illb, IL6, and Ifng expression was determined using CFX-96 ${ }^{\circledR}$ (Bio-Rad, Richmond, CA, USA) and normalized to levels of the housekeeping gene, Gapdh. TNF- $\alpha$ and IFN- $\gamma$ concentration in the supernatant $24 \mathrm{~h}$ after treatment was measured using a commercial ELISA kit (BioLegend) according to the manufacturer's protocol.

\section{Generation of peptide IV-Deficient Mice}

To delete the nucleotide sequence encoding peptide $L v$, we designed two guide RNAs (gRNAa, b) comprising 20-nucleotide sequences targeting exon 2 of the peptide Lv gene (5'-CTGTGGTGCTCTCAATGTCA- $3^{\prime}$ and $5^{\prime}$-ACCTCTCATTTCCGTCGCCG-3'). The two gRNAs coupled with constant regions of CRISPR RNA (crRNA) and trans-activating crRNA (tracrRNA) were obtained from Thermo 
Fisher Scientific (Carlsbad, CA, USA). Along with the gRNAs, Cas9 proteins (Integrated DNA Technologies, Coralville, IA, USA) were electroporated into fertilized C57BL/6J zygotes according to a previously published protocol (19). The zygotes were incubated and surviving two-cell-stage embryos were subsequently transferred into the oviducts of pseudo-pregnant female ICR mice.

\section{Genotyping}

Deletion of the target sequence encoding peptide $L v$ was verified by extracting genomic DNA from tissue samples and performing PCR. The specific primer sets for $\Delta L v$ mice were F1: $5^{\prime}$-CTTCAGAATTCCAGGTGTTTCC-3' and R1: $5^{\prime}$ AGTGTCCAAGAGCTGTCCTCAT-3'. DNA was amplified for 35 cycles at $94^{\circ} \mathrm{C}$ for $20 \mathrm{~s}, 60^{\circ} \mathrm{C}$ for $20 \mathrm{~s}$, and $72^{\circ} \mathrm{C}$ for $20 \mathrm{~s}$ using Ex-Taq DNA polymerase (Takara Bio, Shiga, Japan). Mice with the deleted allele showed a band at $413 \mathrm{bp}$, while wild-type mice showed a band at $777 \mathrm{bp}$. The $\Delta L v$ mouse line was screened based on the genomic DNA sequence. Peptide Lv transcripts were obtained by performing PCR using cDNA samples from BMM and synovial tissue taken from wild-type and peptide $L v$-deficient mice. The following primers were used to detect peptide Lv (299 bp) transcripts: F2, 5'-CTATGGGAACTTCAGCCGGAC- $3^{\prime}$ and R2, 5' -AGCACACAAGGACAGCGTA-3'.

\section{Effect of Peptide-Lv Deficiency on LPS-Mediated TNF- $\alpha$ and IFN- $\gamma$ Production} BMMs were isolated from C57BL/6J mice and peptide Lvdeficient mice as described above. BMMs were exposed to vehicle $(\alpha$-MEM) or $1 \mu \mathrm{g} / \mathrm{ml}$ LPS (Enzo Life Sciences Inc) for 6 and $24 \mathrm{~h}$. Tnfa and Ifng expression was evaluated using qRT-PCR. TNF$\alpha$ and IFN- $\gamma$ concentration in the supernatant $24 \mathrm{~h}$ after LPS treatment was evaluated using ELISA, as described above.

\section{Induction of Synovial Inflammation}

Ten-week-old wild-type (C57BL/6J) and peptide $L v$-deficient mice were kept in a semibarrier system at $23^{\circ} \mathrm{C} \pm 2^{\circ} \mathrm{C}$ and $55 \pm$ $10 \%$ humidity under a 12-h light/dark cycle in Nippon Charles River Laboratories (Kanagawa, Japan) for the duration of the study. Synovial inflammation was induced by performing medial parapatellar arthrotomy in one knee of anesthetized wild-type and peptide $L v$-deficient mice (20). The knee joint was extended and the patella was dislocated laterally. After completely flexing the knee joint again, the rectus femoris was sutured on the lateral side, followed by the skin. One week after injury, synovial specimens were harvested and homogenized with Trizol $(n=5)$. Total RNA extraction, cDNA synthesis, and qPCR for Tnfa and Ifng were performed as described above.

\section{Statistical Analysis}

Bonferroni multiple comparisons test with one-way analysis of variance was used to determine differences among the vehicle, LPS, and LPS + Peptide Lv treatment groups at each time point. Following a Kolmogorov-Smirnov test, a $t$-test or Mann-Whitney $U$-test was used to compare differences between means (SD) from wild-type and peptide $L v$-deficient mice. All statistical analyses were performed using SPSS version 19.0
(IBM Corp., Chicago, IL, USA). $P<0.05$ was considered statistically significant.

\section{RESULTS}

\section{Effect of Peptide Lv on LPS-Mediated Inflammatory Cytokine Expression in BMM}

We studied the effect of peptide Lv on BMM. Exposure to LPS caused a significant rise in Tnfa, Il1b, Il6, and Ifng at $6 \mathrm{~h}$ (Tnfa, $p=0.004$; Illb, $p<0.001$; Il6, $p<0.001$; Ifng, $p=0.010$; Figures 1A-D) and $24 \mathrm{~h}($ Tnfa, $p=0.009 ;$ Illb, $p=0.001 ;$ Il6, $p<$ 0.001 ; Ifng, $p=0.0109)$. Peptide Lv suppressed the LPS-mediated elevation in Tnfa and Ifng expression at $6 \mathrm{~h}(\operatorname{Tnfa}, p=0.015$; Ifng, $p=0.011$ ) and $24 \mathrm{~h}$ (Tnfa, $p=0.002$; Ifng, $p=0.049$ ). In contrast, there were no changes in $I l 1 b$ or Il6 expression in the presence of peptide Lv. LPS significantly increased TNF- $\alpha$ and IFN- $\gamma$ protein concentrations in the supernatant (TNF- $\alpha, p<$ 0.001 ; IFN- $\gamma, p=0.012$; Figures 2A,B). These elevated TNF- $\alpha$ and IFN- $\gamma$ protein concentrations were significantly reduced in the presence of peptide Lv (TNF- $\alpha, p=0.029$; IFN- $\gamma, p=0.044$; Figures 2A,B).

\section{Effect of Peptide Lv Deficiency on TNF- $\alpha$ Expression}

Given our finding that peptide Lv diminished LPS-mediated TNF- $\alpha$ and IFN- $\gamma$ production in BMM, we genetically deleted peptide Lv to investigate its role in macrophages and synovitis. We designed two gRNAs to delete exon 2 from the peptide Lv gene in mice using CRISPR/Cas9 (Figure 3A). Peptide Lv-deficient mouse founders (Figure 3B) were crossed with C57BL/6J mice to generate $\mathrm{F} 1$ progeny. Genotyping confirmed that all F1 mice were missing exon 2 of the peptide $L v$ gene (Figure $3 \mathrm{C}$ ). The predicted amino acid sequence of the deleted peptide Lv portion of the Vstm 4 protein is shown in Figure 3D. RT-PCR confirmed that peptide $L v$ was successfully deleted in BMM and synovial tissue was taken from a peptide $L v$-deficient mouse (Figure $3 \mathbf{E}$ ).

There were no differences in Tnfa and Ifng expression between vehicle-stimulated BMM derived from wild-type and peptide $L v$-deficient mice at $6 \mathrm{~h}$ (Tnfa, $p=0.917$; Ifna, $p=$ 0.602; Figures 4A,B) or $24 \mathrm{~h}$ (Tnfa, $p=0.917$; Ifna, $p=$ 0.175 ; Figures $4 A, B)$. In contrast, stimulation of BMM with LPS significantly increased Tnfa expression in BMM derived from peptide $L v$-deficient mice compared to wild-type mice ( $6 \mathrm{~h}, p=$ $0.009 ; 24 \mathrm{~h}, p=0.009$, respectively; Figure 4A). Consistent with our qRT-PCR results, TNF- $\alpha$ protein levels rose in BMM derived from peptide $L v$-deficient mice compared to wild-type mice ( $p=$ 0.001; Figure 4C). While LPS stimulation significantly increased Ifng expression in BMM derived from wild-type mice compared to peptide $L v$-deficient mice at $6 \mathrm{~h}$ ( $p=0.009$; Figure $4 \mathrm{~B})$, it significantly increased Ifng expression in BMM derived from peptide $L v$-deficient mice compared to wild-type mice at $24 \mathrm{~h}$ $(p=0.047$; Figure 4B). IFN- $\gamma$ protein levels increased in BMM derived from peptide $L v$-deficient mice compared to wild-type mice ( $p=0.028$; Figure 4D). 
A

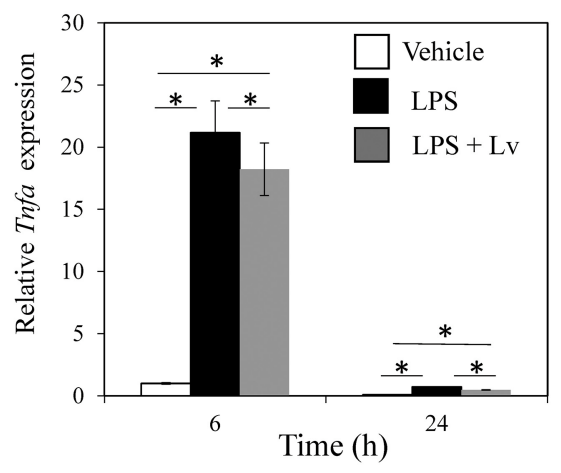

C

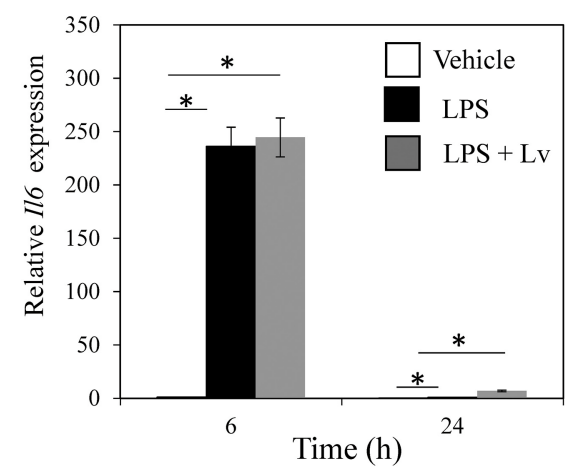

B

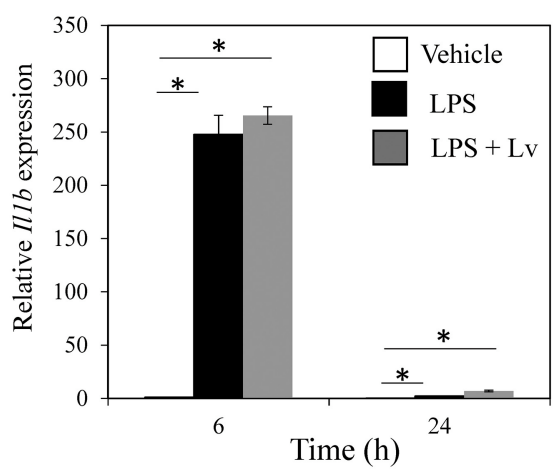

D

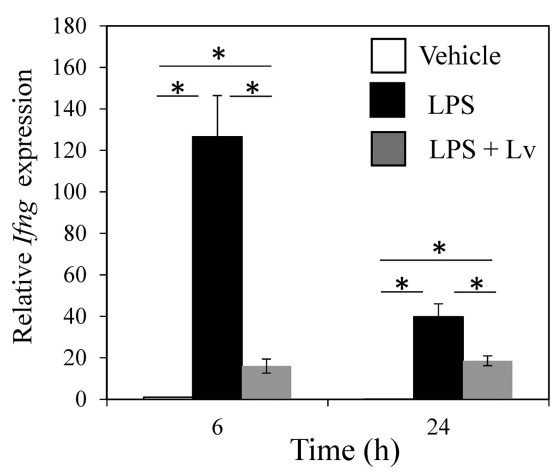

FIGURE 1 | Effect of peptide LV on LPS-mediated inflammatory cytokine production. (A) Tnfa, (B) /11b, (C) I/6, and (D) Ifng expression levels in vehicle-, LPS-, and LPS + peptide LV (LPS + LV)-treated BMM at 6 and $24 \mathrm{~h}$. Relative expression was determined based on the expression in vehicle-treated BMM at $6 \mathrm{~h}$. (B) TNF- $\alpha$ protein levels in the culture supernatant of vehicle-, LPS-, and LPS + peptide Lv (LPS + Lv)-treated BMM. Values are mean \pm SE $(n=8) .{ }^{*} p<0.05$.

\section{A}

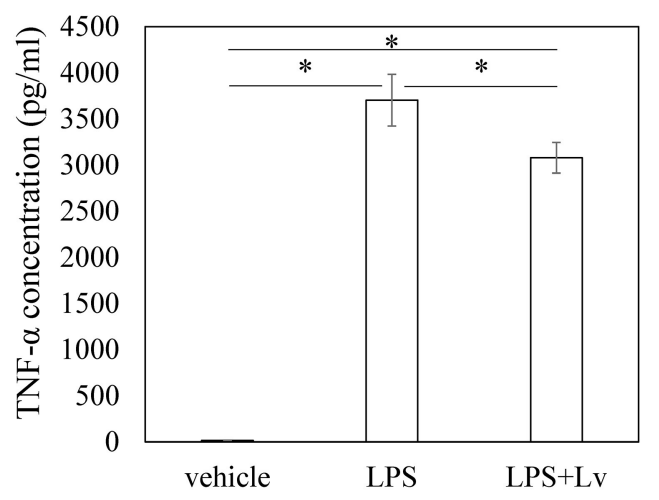

B

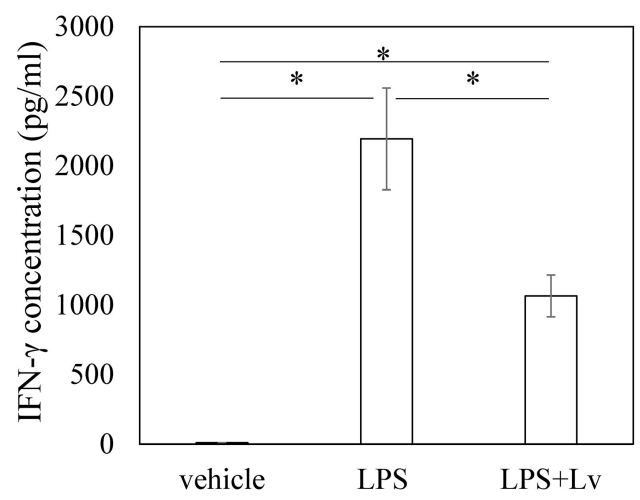

FIGURE 2 | Effect of peptide Lv on LPS-mediated TNF- $\alpha$ and IFN- $\gamma$ production. (A) TNF- $\alpha$ and (B) IFN- $\gamma$ protein levels in the culture supernatant of vehicle-, LPS-, and LPS + peptide Lv (LPS+Lv)-treated BMM. Values are mean $\pm \mathrm{SE}(n=8) .{ }^{*} p<0.05$.

Effect of Peptide Lv Deficiency on Tnfa and Ifng Expression During Synovial

\section{Inflammation}

Tnfa expression levels in the synovium of non-injured wild-type mice were similar to those in non-injured peptide $L v$-deficient mice ( $p=0.713$; Figure 5A). Synovial Tnfa expression increased after injury in both wild-type and peptide $L v$-deficient mice compared to the non-injured synovium $(p=0.009$ and $p=0.009$, respectively). However, synovial Tnfa expression after injury was markedly higher in peptide $L v$-deficient mice than wild-type mice ( $p=0.011$; Figure 5A). No significant differences were observed in Ifng expression between wild-type and peptide Lv-deficient 
A

Vstm4 locus

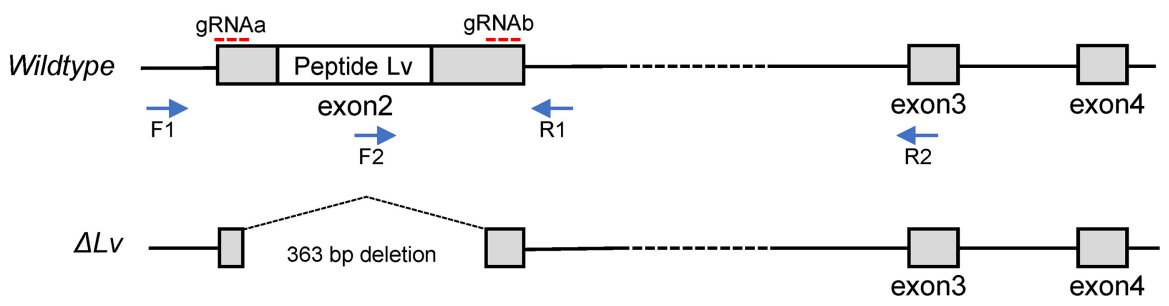

B

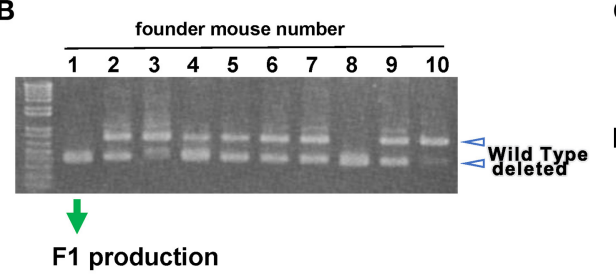

C 5' -GGTGCTCTCAATGCGACGGAAATGAGAGTGATCTCC $\begin{array}{lllllllllllll}G & A & L & N & A & T & E & M & R & V & I & S\end{array}$

D MRLRLLALAAAVLLGPAPEVCGALN TVSPGVVDYLEGE RIIOYYGNESRTANOORLRLIEE R GVLYRTSVLTLRPTD SSFEKKKVTWAFFEDLYVYAVLVCCVGILSVLLFTLVIAW TM QSVFHKRKSRVRHYLVKCPQNSSGETVTSVTSLAPLQPQK GKRQKKKVDVPPAVPAKAPIATTFHKPKLLKPQRKVALPK ITEENLTYAELELIKPHRAAKGVPTSTVYAQILFEENQL

E

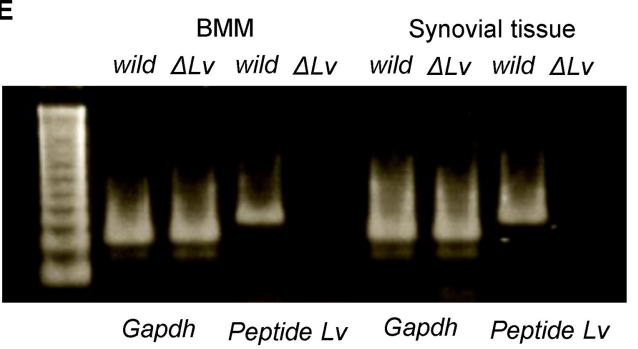

FIGURE 3 | Generation of peptide LV-deficient mice. (A) A map of the mouse Vstm4 locus showing the target regions of the gRNAs and primers used for polymerase chain reaction (PCR). (B) Results of genotyping using PCR to screen for peptide Lv-deficient founder mice. (C) The sequence at the junction of the deleted genes. (D) The predicted amino acid sequence of deleted peptide LV in mouse line No. 1M1. Gray letters are the deleted amino acid sequences. (E) Results of RT-PCR to confirm the depletion of LV.

mice before or after injury (day $0, p=0.347$; day $7, p=1.000$; Figure 5B).

\section{DISCUSSION}

Previous studies have reported that the VSTM family of proteins suppresses T cells and that recombinant VSTM proteins inhibit T cell function in vitro. Recombinant VSTM4 significantly reduces the production of inflammatory cytokines including IFN- $\gamma$, IL-2, and IL-17 by T cells (12). Here, synthetic peptide Lv inhibited LPS-mediated TNF- $\alpha$ and IFN- $\gamma$ production, while peptide Lv deficiency increased TNF- $\alpha$ and IFN- $\gamma$ production in LPSstimulated BMM. Our results suggest that peptide Lv may impart anti-inflammatory action on macrophages.

Peptide Lv can interact with the VEGF receptor and trigger downstream signaling in cardiomyocytes (13). Several studies have reported the protective effects of VEGF on inflammatory stimuli $(15,21)$. VEGF inhibited LPS-mediated apoptosis in endothelial cells (15) and suppressed LPS-mediated M1 polarization in a human monocyte cell line (21). While the mechanism by which peptide Lv regulates TNF- $\alpha$ in our study remains unclear, it is possible that it may involve the VEGF-like actions of peptide Lv.

Studies have shown that TNF- $\alpha$ also regulates the production of pain molecules such as nerve growth factor, calcitonin generelated peptide, and cycloxgenase-2 (5). In the present study, Tnfa expression levels were increased in the synovium of peptide $L v$-deficient mice. TNF- $\alpha$ is a major molecular component of and drug target for OA (22-25). A TNF- $\alpha$ inhibitor has been shown to improve synovitis and pain in a patient with inflammatory KOA (23). Moreover, intra-articular injections of an anti-TNF- $\alpha$ antibody in a recent pilot study significantly improved KOA symptoms and progression $(22,24)$. Given that peptide Lv suppresses TNF- $\alpha$ expression, peptide Lv may be a useful therapeutic target for OA.

IFN- $\gamma$ is primarily produced by $\mathrm{T}$ cells and natural killer cells and contributes to macrophage activation (26). 
A

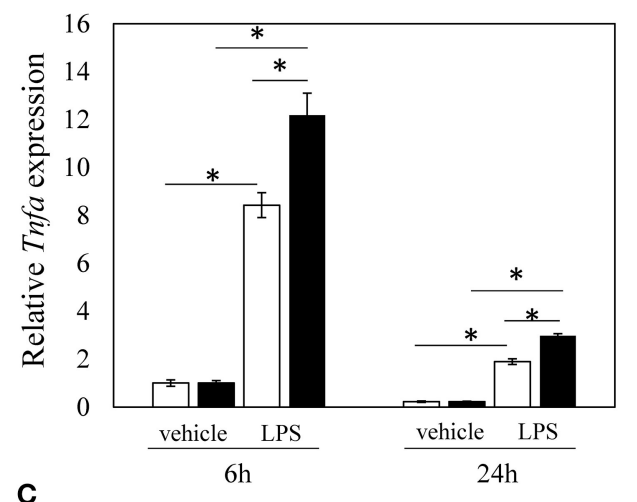

C

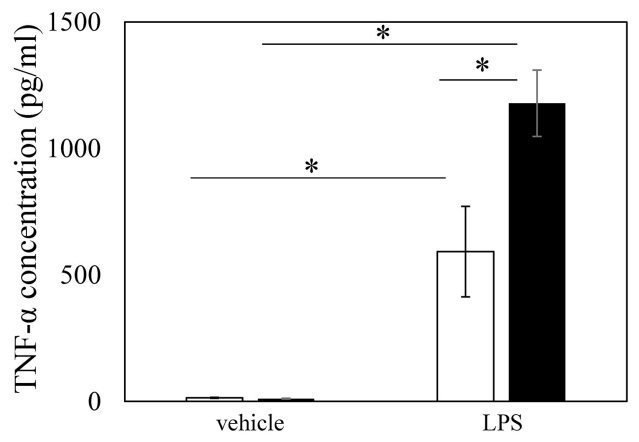

B

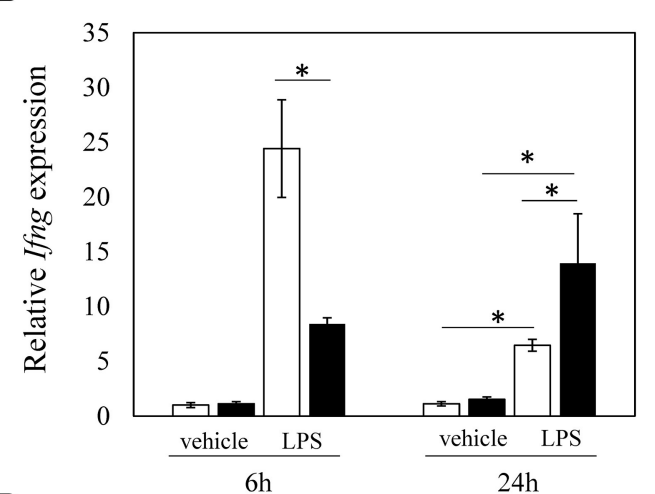

D

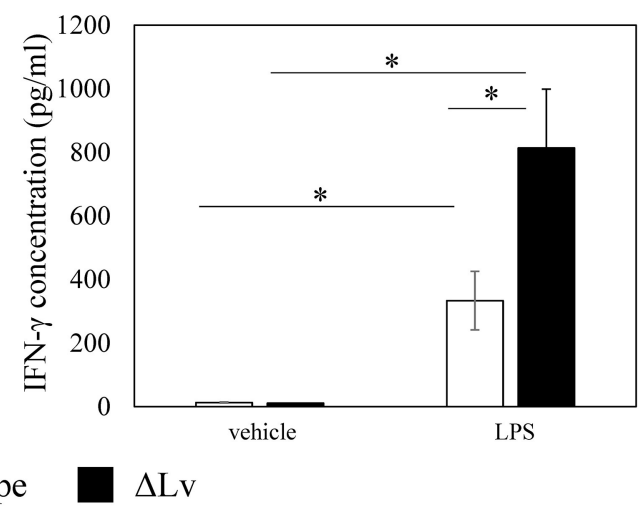

FIGURE 4 | Effect of peptide Lv deficiency on LPS-mediated TNF- $\alpha$ and IFN- $\gamma$ production. (A) Tnfa and (B) Ifng expression levels in vehicle- and LPS-treated BMM obtained from wild-type and peptide $L v$-deficient $(\Delta L v)$ mice. Relative Tnfa expression was determined based on the expression in vehicle-treated BMM. (C) TNF- $\alpha$ and (D) IFN- $\gamma$ protein levels in the culture supernatant of vehicle- and LPS-treated BMM obtained from wild-type and $\Delta$ Lv mice. Values are mean \pm SE $(n=8)$. ${ }^{*} p<0.05$.

\section{A}

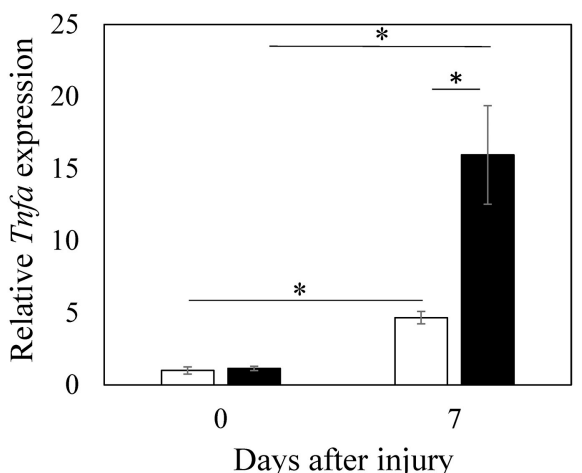

B

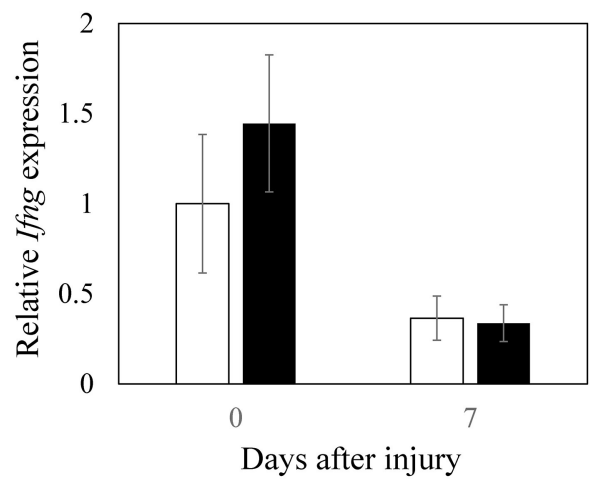

Wildtype $\square \mathrm{Lv}$

FIGURE 5 | Effect of peptide Lv deficiency on Tnfa and Ifng expression in synovium. (A) Tnfa and (B) Ifng expression in synovial tissue obtained from wild-type and peptide $L v$-deficient $(\Delta L v)$ mice with synovitis. Values are mean $\pm \operatorname{SE}(n=5)$. * $p<0.05$.

However, previous studies have showed that macrophages also produce IFN- $\gamma$ and are stimulated by LPS $(27,28)$. Given that a fusion protein containing the extracellular domain of
VSTM4 fused to Fc (VSTM4-Fc) was shown to inhibit IFN$\gamma$ production in human $\mathrm{T}$ cells (12), we evaluated the effect of the VSTM4 fragment on IFN- $\gamma$ expression in macrophages. 
We found that peptide Lv suppressed IFN- $\gamma$ production, while peptide $\mathrm{Lv}$ deficiency increased IFN- $\gamma$ production in macrophages. A previous study of bacterial infection reported that macrophage-derived IFN- $\gamma$ can activate macrophages via an autocrine/paracrine pathway (29). Together with previous studies, our results suggest that peptide Lv may suppress macrophage activation via IFN- $\gamma$ production. However, in our study, synovial Ifng expression did not increase after injury in either wild-type or peptide $L v$-deficient mice. Therefore, the role that peptide Lv plays in IFN- $\gamma$ expression during synovial inflammation remains unclear. Further investigation is needed.

Several limitations warrant mention. First, we only studied the effects of a single dose of peptide Lv in the in vitro study. Second, the effect of peptide Lv on TNF- $\alpha$ was examined in BMM. These data cannot be directly extrapolated to synovial macrophages. Further investigation using synovial macrophages is needed. Third, the mechanism by which peptide Lv affects TNF- $\alpha$ in macrophages remains unclear. Finally, although synovial Tnfa expression was elevated in peptide $L v$-deficient mice, it remains unclear whether this outcome is due to the effect of macrophages.

\section{CONCLUSION}

Macrophages express VSTM4 and its fragment, peptide Lv. Peptide Lv suppressed TNF- $\alpha$ and IFN- $\gamma$ production in macrophages, while peptide $\mathrm{Lv}$ deficiency increased Tnfa expression in the inflamed synovium. Peptide Lv may thus be a therapeutic target for synovial inflammation.

\section{REFERENCES}

1. Lietman C, Wu B, Lechner S, Shinar A, Sehgal M, Rossomacha E, et al.Inhibition of Wnt/beta-catenin signaling ameliorates osteoarthritis in a murine model of experimental osteoarthritis. JCI Insight. (2018) 3:e96308. doi: 10.1172/jci.insight.96308

2. Bondeson J, Wainwright SD, Lauder S, Amos N, Hughes CE. The role of synovial macrophages and macrophage-produced cytokines in driving aggrecanases, matrix metalloproteinases, and other destructive and inflammatory responses in osteoarthritis. Arthritis Res Ther. (2006) 8:R187. doi: 10.1186/ar2099

3. Takano S, Uchida K, Inoue G, Miyagi M, Aikawa J, Iwase D, et al. Nerve growth factor regulation and production by macrophages in osteoarthritic synovium. Clin Exp Immunol. (2017) 190:235-43. doi: 10.1111/cei.13007

4. Uchida K, Satoh M, Inoue G, Onuma K, Miyagi M, Iwabuchi K, et al. $\mathrm{CD} 11 \mathrm{c}(+)$ macrophages and levels of TNF-alpha and MMP-3 are increased in synovial and adipose tissues of osteoarthritic mice with hyperlipidaemia. Clin Exp Immunol. (2015) 180:551-9. doi: 10.1111/cei.12607

5. Uchida K, Takano S, Matsumoto T, Nagura N, Inoue G, Itakura M, et al. Transforming growth factor activating kinase 1 regulates extracellular matrix degrading enzymes and pain-related molecule expression following tumor necrosis factor-alpha stimulation of synovial cells: an in vitro study. BMC Musculoskelet Disord. (2017) 18:283. doi: 10.1186/s12891-017-1648-4

6. Sergijenko A, Roelofs AJ, Riemen AH, De Bari C. Bone marrow contribution to synovial hyperplasia following joint surface injury. Arthritis Res Ther. (2016) 18:166. doi: 10.1186/s13075-016-1060-8

7. Sun W, Zhang H, Wang H, Chiu YG, Wang M, Ritchlin CT, et al. Targeting notch-activated M1 macrophages attenuates joint tissue damage in

\section{DATA AVAILABILITY STATEMENT}

The original contributions presented in the study are included in the article/supplementary material, further inquiries can be directed to the corresponding author/s.

\section{ETHICS STATEMENT}

The animal study was reviewed and approved by All experimental protocols received approval from the Kitasato University School of Medicine Animal Care Committee (2020-087).

\section{AUTHOR CONTRIBUTIONS}

$\mathrm{MM}, \mathrm{KU}$, and MT designed the experiments. MM, KU, TO, ST, TM, MS, and GI collected the data. MM, ST, TM, MS, and GI performed data analysis and interpretation. $\mathrm{MM}$ and $\mathrm{KU}$ wrote the manuscript. All authors have read the manuscript and provided intellectual content.

\section{FUNDING}

This investigation was supported in part by Grant-in-Aid for Young Scientists (Start-Up) No. 19K24037 and by a Kitasato University Research Grant for Young Researchers.

\section{ACKNOWLEDGMENTS}

We thank Ms. Mai Matsumoto and Ms. Yuko Onuki for their assistance with PCR analysis.

a mouse model of inflammatory arthritis. J Bone Miner Res. (2017) 32:146980. doi: $10.1002 /$ jbmr.3117

8. Uchida K, Naruse K, Satoh M, Onuma K, Ueno M, Takano S, et al. Increase of circulating $\mathrm{CD} 11 \mathrm{~b}(+) \mathrm{Gr} 1(+)$ cells and recruitment into the synovium in osteoarthritic mice with hyperlipidemia. Exp Anim. (2013) 62:255-65. doi: 10.1538/expanim.62.255

9. Dong Y, Zhang Y, Kang W, Wang G, Chen H, Higashimori A, et al. VSTM2A suppresses colorectal cancer and antagonizes Wnt signaling receptor LRP6. Theranostics. (2019) 9:6517-31. doi: 10.7150/thno.34989

10. Levin SD, Taft DW, Brandt CS, Bucher C, Howard ED, Chadwick EM, et al. Vstm3 is a member of the CD28 family and an important modulator of T-cell function. Eur J Immunol. (2011) 41:902-15. doi: 10.1002/eji.201041136

11. Secco B, Camire E, Briere MA, Caron A, Billong A, Gelinas Y, et al. Amplification of adipogenic commitment by VSTM2A. Cell Rep. (2017) 18:93-106. doi: 10.1016/j.celrep.2016.12.015

12. Wang J, Manick B, Renelt M, Hansen L, Person A, Kalabokis V, et al. VSTM4 is a novel negative regulator of T cell activation. J Immunol. (2019) 202(1 supplement):124.4.

13. Shi L, Ko ML, Abbott LC, Ko GY. Identification of Peptide lv, a novel putative neuropeptide that regulates the expression of L-type voltage-gated calcium channels in photoreceptors. PLOS ONE. (2012) 7:e43091. doi: 10.1371/journal.pone.0043091

14. Shi L, Zhao M, Abbey CA, Tsai SH, Xie W, Pham D, et al. Newly identified Peptide, Peptide Lv, promotes pathological angiogenesis. J Am Heart Assoc. (2019) 8:e013673. doi: 10.1161/JAHA.119.013673

15. Koh H, Tasaka S, Hasegawa N, Yamada W, Shimizu M, Nakamura M, et al. Protective role of vascular endothelial growth factor in endotoxin-induced acute lung injury in mice. Respir Res. (2007) 8:60. doi: 10.1186/1465-9921-8-60 
16. Lai YS, Wahyuningtyas R, Aui SP, Chang KT. Autocrine VEGF signalling on M2 macrophages regulates PD-L1 expression for immunomodulation of T cells. J Cell Mol Med. (2019) 23:1257-67. doi: 10.1111/jcmm.14027

17. Li N, Qin J, Lan L, Zhang $\mathrm{H}$, Liu F, Wu Z, et al. PTEN inhibits macrophage polarization from M1 to M2 through CCL2 and VEGFA reduction and NHERF-1 synergism. Cancer Biol Ther. (2015) 16:297-306. doi: 10.1080/15384047.2014.1002353

18. Kawakubo A, Uchida K, Miyagi M, Nakawaki M, Satoh M, Sekiguchi H, et al. Investigation of resident and recruited macrophages following disc injury in mice. J Orthop Res. (2020) 38:1703-9. doi: 10.1002/jor.24590

19. Okubo T, Hara K, Azuma S, Takada S. Effect of retinoic acid signaling on Ripply3 expression and pharyngeal arch morphogenesis in mouse embryos. Dev Dyn. (2021) 250:1036-50. doi: 10.1002/dvdy.301

20. Takano S, Uchida K, Miyagi M, Inoue G, Aikawa J, Iwabuchi K, et al. Adrenomedullin regulates IL-1beta gene expression in F4/80+ macrophages during synovial inflammation. J Immunol Res. (2017) 2017:9832430. doi: 10.1155/2017/9832430

21. Wheeler KC, Jena MK, Pradhan BS, Nayak N, Das S, Hsu CD, et al. VEGF may contribute to macrophage recruitment and M2 polarization in the decidua. PLoS ONE. (2018) 13:e0191040. doi: 10.1371/journal.pone.0191040

22. Fioravanti A, Fabbroni M, Cerase A, Galeazzi M. Treatment of erosive osteoarthritis of the hands by intra-articular infliximab injections: a pilot study. Rheumatol Int. (2009) 29:961-5. doi: 10.1007/s00296-009-0872-0

23. Grunke M, Schulze-Koops H. Successful treatment of inflammatory knee osteoarthritis with tumour necrosis factor blockade. Ann Rheum Dis. (2006) 65:555-6. doi: 10.1136/ard.2006.053272

24. Guler-Yuksel M, Allaart CF, Watt I, Goekoop-Ruiterman YP, de Vries-Bouwstra JK, van Schaardenburg D, et al. Treatment with TNF-alpha inhibitor infliximab might reduce hand osteoarthritis in patients with rheumatoid arthritis. Osteoarthritis Cartilage (2010) 18:1256-62. doi: 10.1016/j.joca.2010.07.011

25. Magnano MD, Chakravarty EF, Broudy C, Chung L, Kelman A, Hillygus J, et al. A pilot study of tumor necrosis factor inhibition in erosive/inflammatory osteoarthritis of the hands. J Rheumatol. (2007) 34:1323-7.

26. Trinchieri G. Interleukin-12 and the regulation of innate resistance and adaptive immunity. Nat Rev Immunol. (2003) 3:133-46. doi: 10.1038/nri1001

27. Di Marzio P, Puddu P, Conti L, Belardelli F, Gessani S. Interferon gamma upregulates its own gene expression in mouse peritoneal macrophages. J Exp Med. (1994) 179:1731-6. doi: 10.1084/jem.179.5.1731

28. Fultz MJ, Barber SA, Dieffenbach CW, Vogel SN. Induction of IFNgamma in macrophages by lipopolysaccharide. Int Immunol. (1993) 5:138392. doi: 10.1093/intimm/5.11.1383

29. Rothfuchs AG, Gigliotti D, Palmblad K, Andersson U, Wigzell H, Rottenberg ME. IFN-alpha beta-dependent, IFN-gamma secretion by bone marrowderived macrophages controls an intracellular bacterial infection. J Immunol. (2001) 167:6453-61. doi: 10.4049/jimmunol.167.11.6453

Conflict of Interest: The authors declare that the research was conducted in the absence of any commercial or financial relationships that could be construed as a potential conflict of interest.

Publisher's Note: All claims expressed in this article are solely those of the authors and do not necessarily represent those of their affiliated organizations, or those of the publisher, the editors and the reviewers. Any product that may be evaluated in this article, or claim that may be made by its manufacturer, is not guaranteed or endorsed by the publisher.

Copyright (c) 2021 Mukai, Uchida, Okubo, Takano, Matsumoto, Satoh, Inoue and Takaso. This is an open-access article distributed under the terms of the Creative Commons Attribution License (CC BY). The use, distribution or reproduction in other forums is permitted, provided the original author(s) and the copyright owner(s) are credited and that the original publication in this journal is cited, in accordance with accepted academic practice. No use, distribution or reproduction is permitted which does not comply with these terms. 